\title{
Emerging Trend in the Culture of Domestic Violence against Men in Southern Nigeria
}

\author{
Barr. Emmanuel Imuetinyan Obarisiagbon, Ph.D. \\ Department of Sociology \& Anthropology \\ Faculty of Social Sciences \\ University of Benin, Benin City \\ Mr. Mannie I. Omage \\ Department of Sociology and Anthropology \\ Benson Idahosa University \\ Benin City, Nigeria
}

\begin{abstract}
Hitherto domestic violence was seen as one perpetrated by men against women and that men were not in any way victims of domestic violence. Recent studies indicate that intimate partner violence in Nigeria is no longer a rarity but a reality with varying degrees of implications on the individuals and the society at large. The society therefore through the use of both quantitative and qualitative research technique sought to investigate the existence of domestic violence against men and the motives behind their occurrences. Delta and Edo States in Southern Nigeria were chosen as the study area while respondents were randomly selected from the state capitals of Benin and Asaba respectively. With the aid of snowballing sampling method, in-depth interviews were conducted on some respondents. The findings of the study revealed that domestic violence against men exists in Nigeria and the motives range from self-defence, provocation, infidelity, financial hardship and drunkenness. The study therefore suggests that government agencies, civil societies and religious bodies should do more advocacies on its reality and impact on homes and the society while law enforcement agents should be alive to their responsibility.
\end{abstract}

Keywords: Intimate partner violence, battered husbands, frustration, infidelity, financial hardship

\section{Introduction}

Recently, the social and conventional media has been awashed with terrible stories of women brutally killing and causing bodily harm on their husbands for different reasons. This trending social phenomenon which goes by different names like domestic abuse, spousal abuse, battering, family abuse and very recently, intimate partner violence (IPV) has not received much attention partly due to the fact that men are regarded by the society as the stronger vessels and society does not even believe that they can be abused as the general belief is that, only women are victims of domestic violence. Interestingly, some men who suffer physical and domestic abuse silently and believe no one cares about them. Even when they try to confide in someone, such men are reduced to a butt of society jokes. So they just continue to be invisible victims.

Domestic violence against men is a global issue and over the last couple of years, recognition of its scope and significance has increased. According to Fink (2006), in the USA, domestic violence has affected $7.6 \%$ of males, while in South Africa, 4 in every reported 10 domestic violence cases, are men (WHO, 2002). Smith's (2002) study shows that $7 \%$ of women and $4 \%$ of men were victims of domestic violence. Similarly, statistics revealed that in Kenya, Zambia and Tanzania, domestic violence against men is prevalent (WHO, 2002). The works of Deinye (2008), Namadi (2017), Adebayo (2014) indicate that domestic violence against men in Nigeria is no longer a rarity but a reality and its prevalence is on the increase. This is further attested to by Barber (2008) when he stated that a male is abused by his female partner every 14.6 seconds. True, the subject of men being abused in any form by their spouses is a very delicate or rather sensitive one. Men generally, are likely to get worried about the stigma and ridicule they may get, should they even admit that their spouses are violent towards them.

Mutepfa (2009) acknowledges the existence of domestic violence against men and that women are capable of abusing men in a marriage. Kumar's (2012) study shows that husbands are also at the receiving end of acts of physical aggression. Similarly, Namadi (2017) confirms that domestic violence against men exist and it is in varied forms. His study refutes the age-long held belief that husbands are the ones that dealt treacherously and violently with their wives. He concludes based on his study that domestic violence against men is a reality in present day Nigeria. 
Majority, if not all African societies as noted by Maboreke (2009) are basically patriarchal and so, violence against men is not something to be talked about, as men are thought to be able to defend themselves. Sadly, a man in an African society who reports his wife as abusing him is regarded as a weakling. This perhaps, explains why the study of domestic violence seems to have been limited in scope to women. The overall implication of this development tells a lot about why violence against men tend to go unnoticed and consequently makes the extent of the issue to remain unknown and understudied in Nigeria.

It is not surprising therefore; that lower number of cases is reported in less developing (African) societies with less attention and support. Interestingly, this trend according to Watts and Zimmerman (2002) appears not to be peculiar to African societies but is a global issue and may be due to the sensitive nature of the subject. In Nigeria, there are diverse reasons for domestic violence against men and this range from infidelity (Fiktee and Bhan, 1999), drunkenness and cultural norms (IIika, Okonkwo and Adogu, 2002), self defence and provocation (Johnson, 2001), financial demands or unfulfilled financial needs (Dienye, 2009). Adebayo (2014) reveals that battered men cut across all ages, educational levels and socio-economic classes and that the occurrence of domestic violence against men leaves them depressed and anxious and consequently lead them into substance abuse, unprotected sex to mention but a few. Considering the under reporting of this social menace, this study seeks to determine its occurrence and factors that encourage it.

\section{Research objectives}

This study seeks to examine the emerging trend in the culture of domestic violence against men in Southern Nigeria. The specific objectives included:

i. to determine whether domestic violence against men exist in Southern Nigeria.

ii.to investigate the causes of domestic violence against men in Southern Nigeria

\section{Research questions}

i. Does domestic violence against men exist in Southern Nigeria?

ii. What are the causes of domestic violence against men in Southern Nigeria?

\section{Brief review of related literature}

One of the emerging contemporary social problems in Nigeria today is husband battery, intimate partner violence (IPV) or what is also referred to as domestic violence more particularly on men. To Oti, Paul and Duru (2017), the issue has become a national topical one especially as the polity is daily awash with reports on spousal killings and attacks occasioning harm. The incidence and prevalence of this issue which is on the rise, and the gradual systematic erosion of family values has thus become an issue worth investigating.

When mention is made of the concept domestic violence, what easily comes to mind is the beating, molestation and brutalization of women by their husbands which is age-long and widespread. This implies that women are the prime subject and remain the target of abusers. Odumakin (2006) worried about the alarming rate of domestic violence against women in particular. He noted that of the 2,400 cases of domestic violence handled by her office; only an infinitesimal portion -2- cases were against men. This lends credence to the motion that women are often held to be the victims of domestic violence. McKeown and Kidd (2003) have observed men who are victims of domestic violence face a society that believes that wives are the only victims and husbands are the abusers. This general notion is constantly being reinforced by the several media campaign against the abuse of women in intimate relationship and the sympathy and support they receive while male victims are treated with utter disbelief (Cleary, 2003). However, in the last couple of years, abusive behaviour against men has come to the fore as the media has reported some very terrible and horrible killings by women of their husbands. In fact, traditionally, the man is always seen as the aggressor while the women are the victims. Little or no research provides insight into the risk a man faces if he is assaulted by a woman in an intimate relationship (Heise and Gottenmoeller, 1999).

\section{Incidence and prevalence of domestic violence against men}

On the $4^{\text {th }}$ of February, 2015, one Victoria Gagariga murdered her husband, Henry Gagariga in their residence at Yenagoa, Bayelsa State. After three years of prosecution in the court, the trial judge found her guilty and consequently sentenced her to death y hanging (Nwachukwu, 2018). Similarly, one Maryam Sanda of Wuse 2, Abuja stabbed her husband, Haliru Bello Bilyaminu to death (Osazuwa and Ibom, 2018). While in Delta State, the High Court sitting in Effurrun convicted one Mrs. Mary Attah for the murder of her husband, Pastor Darlington Attah on the $6^{\text {th }}$ of July, 2012 with a kitchen knife after immobilizing him by rubbing pepper on his face. Not satisfied, she dosed the bleeding husband with fuel and set him ablaze. 
In the same vein, an Ibadan based lawyer, Yewande Oyediran knifed her husband, Lowo Oyediran to death on the $2^{\text {nd }}$ of February, 2016 at their 30, Adeniyi layout, Abidi-Odan, Akobo, Ibadan home. The state high court in Ibadab subsequently found her guilty of the offence and sentenced her to 7 years imprisonment on the $27^{\text {th }}$ November, 2017 (Adezion, 2018). Another pathetic incidence of husband killing took place at Diamond estate, Sangotedo, Lagos State on the $3^{\text {rd }}$ of May, 2018 when one Barr. Udeme stabbed her husband, Otike Odubi to death. She went further to cut off the man's penis and laid it on his right hand (Nwafor, 2018).

\section{Forms of domestic violence against men}

Intimate partner violence takes different forms but the most common shape it takes includes:

Verbal abuse: this refers to the use of excessive language to cast aspersion on a man's integrity and dignity. It could also take the form of insult and mockery. It is a common sight to behold in Nigeria, for a woman during a quarrel or disagreement to pour out different invectives on the husband ranging from; "you are not ashamed", "it is only in the house you have power", "God will punish you", "lazy man", "your mates have houses and cars but you have nothing". Physical abuse: this usually involves a contact on another person which is meant to cause grievous bodily injury, pain or impairment. Cork Rape Crisis Centre (2002) identified this form of abuse to include pushing, pinching, damage to property and as Dobash and Dobash (2000) note, it can occur at any time or place. In Nigeria, a man physically abused by his spouse can easily be known by the finger marks on his face and teeth bites on his body. Extreme cases include injury on his head and legs caused by the use of sharp objects like knives.

Sexual abuse: this kind of abuse is usually committed against men and it is the hardest to disclose in spite of emotional pain that it produces. When men in Nigeria are sometimes accused of forcing their spouses to have sex, women on their part abuse their spouses by denying them sexual intimacy. Some Nigerian women are often in the habit of refusing sexual advances from their spouse by saying they have headaches or are tired. At other times, they mock, deride and use demoralizing words on their spouse. It is not uncommon to hear a woman asking the spouse if sex is food. While frowning and condemning these acts, Obarisiagbon (2017) notes that these are subtle but damaging abuses against men. Emotional/psychological abuse: this refers to degrading or humiliating conducts a wife has towards the husband which might be in the form of repeated insults, ridicule or name calling and keeping malice. Quinn (1997) sees the keeping of malice (physical abuse) as the willful infliction of mental emotional anguish on a spouse.

Economic abuse: granted that in Nigeria, men are expected to provide for their families but in some cases, particularly when due to the economic downturn/recession, some men have found themselves out of work and so are unintentionally not able to meet the economic needs of their families. Nothing can be as painful to a man when due to situation beyond his control, he is unable to meet the needs of his home and the closest person to him mocks him with his predicament. Where a woman finds herself in a position of economic power and thus uses it against her spouse, that is economic abuse- IPV.

\section{Why women are domestically violent against their intimate partners in Nigeria}

Some women take to intimate partner violence due to provocation or in self-defence against their spouses. According to Babcook et al (2003), women who take to intimate partner violence attribute it to defending themselves from their partners. This possibly as Hamberger and Guse (2002) and Johnsons (2001) note is due to the fact that majority of such women have experienced aggression from their husbands and so have learnt to defend themselves albeit violently. Swan and Snow's (2003) study revealed that women who were arrested for domestic violence claimed to have been motivated by self-defence and provocation. Various researches have found that wives who are physically violent against their husbands have at one time or the other battered. These women now strike out to either stop or escape such attacks.

Another possible reason why a wife would become domestically violent towards the husband of her youth could be due to financial demands (Dienye, 2009). Where the husband appears to be unable to cater for her, particularly the children, the woman could be frustrated, especially, if there is no food at home and the children have been driven away from school due to non-payment of school fees. The situation could be further worsened if the man goes out and spends on 'others' to the discovery of the wife.

Infidelity has been attributed by Fiktee and Bhah (1999) as another cause of intimate partner violence. Although, the traditional societies, accepts marrying more than one wife, but the trend today towards monogamy and Christian marriage has made it unfashionable. Many women labour together with their husbands and expect to reap the fruit of their labour when things get better with their husbands. At last, this sometimes is not to be as the man starts money in his pocket starts to womanise thus becoming unfaithful to the wife who has been laboring with him for years. This situation could push the woman to take the laws into her hands by becoming violent. Coker, Smith, Mckerown and King (2000) and Ilika et al (2002) have attributed domestic violence against men to drunkenness and keeping late night. 
Some men when they have come into money suddenly starts patronizing various 'joints' in the locality and consequently come home late in the night and also drunk. This has a way of making the woman feel used, neglected and unwanted. Efforts to talk the man out of this habit most times are met with shoving aside and comments like "how dare you question my authority. Persistence of this, could lead the woman into frustration and the twin aggression.

\section{Theoretical explication}

This study adopts the frustration aggression theory. This theory is closely associated with Dollard, Doob, Miller, Mowrer and Sears (1939) who held that the happening of aggressive actions always presupposes the existence of frustration and contrariwise, that the existence of frustration naturally gives rise to aggression. This implies that frustration is the preventing of a goal response, and a goal response in turn reinforces final operation in an ongoing behaviour sequence. In other words, the existence of frustration always leads to some form of aggression. It must be stated here that frustration are aversive events which tends to generate aggressive inclinations only to the extent that they produce negative effects. And as Berkowitz (1989) stated that any kind of negative thing, sadness, depression and agitated irritability will always have a way of producing aggressive tendencies and the primitive experience of anger before the higher order processing goes into operation.

In relation to the topic under investigation, it is believed that there are certain factors that tend to precipate domestic violence against men. Just like aggression is an end product of frustration as Dollard et al 1939 would say, it is thus believed that infidelity, drunkenness, unfulfilled financial demands are some of the frustrating issues that often times confront women which in turn unfortunately leads to intimate partner violence against men (aggression).

\section{Methods and materials}

This is a cross sectional descriptive study that was conducted in Delta and Edo states, Southern Nigeria. The study used both the qualitative and quantitative research techniques for its data collection. The quantitative technique was used through structured questionnaire schedule canvassed to 1000 respondents who were randomly selected from the state capitals of Delta and Edo States. The qualitative technique was employed through interview schedule canvassed to 30 interviewees who were through snowballing sampling method included in the study, ethical concerns were adequately taken care of by obtaining verbal consent and keeping the anonymity of the respondents. The instrument for data collection was content validated as well as a test, re test carried out with them to determine its reliability. Qualitative data collected with the aid of four research assistants were content analysed with the use of inferential statistics.

Table 1: Demographic characteristics of respondents

\begin{tabular}{|l|c|c|}
\hline & FREQUENCY & PERCENTAGE (\%) \\
\hline Sex & & 50 \\
\hline Male & 494 & 50 \\
\hline Female & 494 & $\mathbf{1 0 0}$ \\
\hline Total & $\mathbf{9 8 8}$ & 10 \\
\hline Age & 100 & 41 \\
\hline $21-30$ & 400 & 35 \\
\hline $31-40$ & 350 & 14 \\
\hline $41-50$ & 138 & - \\
\hline $51-60$ & - & $\mathbf{1 0 0}$ \\
\hline 61 and above & $\mathbf{9 8 8}$ & 93 \\
\hline Total & & 1 \\
\hline Religion & 920 & 6 \\
\hline Christianity & 10 & $\mathbf{1 0 0}$ \\
\hline Islam & 58 & 12 \\
\hline A.T.R. & $\mathbf{9 8 8}$ & 25 \\
\hline Total & & 63 \\
\hline Educational level & 120 & $\mathbf{1 0 0}$ \\
\hline Primary & 250 & 86 \\
\hline Secondary & 618 & 5 \\
\hline Tertiary & $\mathbf{9 8 8}$ & $\mathbf{1 0 0}$ \\
\hline Total & & \\
\hline Marital status & 850 & \\
\hline Married & 50 & $\mathbf{9 8 8}$ \\
\hline Separated & & \\
\hline Divorced & & \\
\hline Total & & \\
\hline Suce: field & & \\
\hline
\end{tabular}

Source: field survey, 2019 
Table 1 summarizes the results of the demographic characteristics of the respondents. It shows that among the 988 respondents who participated in the study, $50 \%$ of them were male and female respectively. $10 \%$ were in the 21-30 years age range, $41 \%$ were between $31-40$ years while $35 \%$ were between $41-50$ years and $14 \%$ were $51-60$ years while there was none in the 61 years and above age range. 93\% of the respondents were Christians, $1 \%$ Muslims and $6 \%$ practiced African traditional religion. On educational status, $12 \%$ of the respondents had primary education, $25 \%$ had secondary education while $63 \%$ had tertiary education. For marital status, $86 \%$ of the respondents were married, 95 were separated and $9 \%$ were divorced.

Table 2: The battered man and domestic violence

\begin{tabular}{|l|c|c|}
\hline $\begin{array}{l}\text { Does domestic violence } \\
\text { against men exist in Southern } \\
\text { Nigeria? }\end{array}$ & FREQUENCY & PERCENTAGE (\%) \\
\hline Yes & 728 & 74 \\
\hline No & 260 & 26 \\
\hline Total & $\mathbf{9 8 8}$ & $\mathbf{1 0 0}$ \\
\hline
\end{tabular}

Source: field survey, 2019

Table 2 shows that $74 \%$ of the surveyed population affirmed that domestic violence against men exist in Southern Nigeria while $26 \%$ were in the negative. This finding is further given credence to by the studies of Mutepfa (2009), Kumar (2012) and Namadi (2017) where they noted that violence against men by women is a reality as it occurs from time to time in various places and various forms. The result of this study is further corroborated by the view of one interviewee when he asserted that:

My brother's wife is a husband beater. At the slightest provocation, she pounces on my brother and designs his face with marks from her long finger nails. I often pity my brother but do not involve myself for the love of my face.

(IDI, Male, $20^{\text {th }}$ January, 2019)

Another interviewee simply puts it thus:

It is true that some women do not have respect for their husbands and that is why they raise their hands against their husbands. My husband and I have not only witnessed but rescued my neighbour's husband from his wife's hands. Even though the man, on a good day can beat the wife but because of his Christian faith, he does not do so.

(IDI, Male, 24 ${ }^{\text {th }}$ January, 2019)

Table 2: Women's violence against men and the causes

\begin{tabular}{|l|c|c|}
\hline Causes of violence against men & FREQUENCY & PERCENTAGE (\%) \\
\hline Financial demands & 178 & 18 \\
\hline Provocation/self-defence & 130 & 13 \\
\hline Infidelity & 140 & 14 \\
\hline Drunkenness/keeping late nights & 150 & 16 \\
\hline All of the above & 390 & 39 \\
\hline Total & $\mathbf{9 8 8}$ & $\mathbf{1 0 0}$ \\
\hline
\end{tabular}

Source: field survey, 2019

Table 2 reveals that $18 \%$ of the surveyed population believed that financial demands causes women's violence against men, $11 \%$ held that provocation/self-defence is also a cause of women's violence against men, $14 \%$ agreed that infidelity is another cause while $16 \%$ held on to drunkenness and keeping late night as a cause and 39\% went for all the stated reasons.

The finding of this study validates the previous works of Johnson (2001), Hamberger and Guse (2002), Swan and Snow (2003) and Babcook et al (2003) were they noted that some women end up killing their husbands either in self defence or out of provocation. Similarly, this study findings on financial demands, infidelity and drunkenness/keeping late nights as some of the reasons why women kill their husbands is further given credence to by Dienye (2009), Fiktee and Bhah (1999), Ilika, Okonkwo and Adogu (2002) and Coker, Smith, Mckerown and King (2008) respectively. The result of this study is further collaborated by the view of one interviewee when he asserted that: 
Some women, even though they often regret their actions of violence have often attributed it to the refusal of their spouses to provide for them and their children, leaving them hungry and haggard.

(IDI, Male, Clergyman, $14^{\text {th }}$ January, 2019)

Another interviewee simply puts it thus:

One of the often given reasons for the physical assault against their husbands is self-defence and provocation. They claim they were provoked and sometimes acted in self-defence before they would be killed.

(IDI, Male, Ministry of Women Affairs, $16^{\text {th }}$ January, 2019)

One interviewee who claimed to have battered her husband attributed her action to:

"He comes home not only late but drunk. Sometimes he sleeps out in his mistress' house and tells me to my face that his mistress is better than me in bed. Each time he says that, I give it to him with my gifts- fingers and teeth".

(IDI, female, housewife, $15^{\text {th }}$ January, 2019)

\section{Conclusion and recommendations}

It is a truism that domestic violence against women is evident in Nigeria, but this study has revealed that men suffer as victims of domestic violence as well. In other words, that domestic violence against men being a rarity, has been replaced by its being a reality as shown by this study. Divergent motives were discovered from the study to be responsible for the battering of men by their intimate partners in Nigeria. Based on the findings of this study, it is recommended that there should be more advocacy to enlighten the society about the existence and reality of the ills of domestic violence against men. This enlightenment should be undertaken by approved government agencies, religious organizations and the civil societies. The attitude of the society and the law enforcement agencies should change from trivializing the issue to taking it more seriously as it takes a great deal of effort for men to acknowledge and speak up that they are being abused by their wives. They do not deserve to be ridiculed, mocked or ignored. Infact, the arrest, prosecution of women who domestically aggress their husband should be given the widest publicity in order to serve as deterrence to others who have the potentials to do the same.

\section{References}

Adebayo, A.A. (2014). Domestic violence against men: balancing the gender issues in Nigeria. America Journal of Sociological Research, 4(1):14-19

Adezion, E (2018). In the world of Nigeria's killer wives Nigeria observer, Feb. 17/2019.

Agency report (2010) Lagos records 1338 domestic violence cases against men in 10 months official retrieved from premium on the $19^{\text {th }}$ of April.

Babcock JC, Miller SA and Siard C. (2003) Toward a typology of abusive women: Differences between partneronly and generally violent women in the use of violence. Psychology of Women Quarterly, 27:153-161

Barber, C. F. (2008). Domestic violence against men. Nursing Standard, 22(51):35-39

Berkowitz, L,L (1989) Frustration-aggression hypothesis, examination and reformulation- Psychological Bulletin, 106(1): 59-73.

Cleary, M.T. (2003). Domestic violence against men and children: family violence hurts everyone. Meath: Amen

Coker, A.L., Smith, P.A., Bethea, M.R., King and Mckeown (2010). Physical health consequence of physical and psychological intimate partner violence. Ach family med, 9:451-457

Cork Rape Crisis Centre (2002). Domestic violence. Ireland: http://www.corkrapecrisis.ie/violence.htm(08-Jan-2016)

Dienye, P.P. (2008). Domestic violence against men in primary healthcare in Nigeria. University of Port Harcourt

Dobash, R.E. and Dobash, R.P. (2000). Changing violent men. London: Sage Publications Ltd

Dollard, J. Miller, N., Doob, L, Mowrer, O and Sears, R. (1939) Frustration and Aggression. New Haven, CT, US, Yale University Press

Fiktee, F.F. and Bhah, L.I. (1999). Domestic violence and health of Pakistani women. International Journal of Gynaecology and Obstetrics, 65:195-201

Fink, P.J. (2000). Clinical psychiatry news, 34(10):18

Hamberger, L.K., and Guse, C.E. (2002). Men's and women's use of intimate partner violence in clinical samples. Violence against Women, 8:1301-1331 
Heise, L., Ellsberg, M and Gottenmoeller, M. (1999). Ending violence against women (Population Reports, Series L, No. 11). Baltimore: Population Information Program, John Hopkins University School of Public health.

Johnson, M.P. (2001). Conflict and control: symmetry and asymmetry in domestic violence. In a Booth, A.C. Crouther \& Clement, M. (Eds).Couples in conflict p. 95-105, Mahwah, $\quad$ N.J: Lawrence Erlbaum

Kumar, A. (2012). "Domestic violence against men in India: a perspective". Journal of Human Behaviour in the Social Environment, 22(3):290-296.

Llika, A.L., Okonkwo, P.I. and Adogu, P. (2002). Intimate partner violence among women of childbearing age in a primary healthcare centre in Nigeria. African Journal of Reproductive Health, 6:53-58.

Mckeown, K. and Kidd, P. (2003). Men and domestic violence: what research tells us? Dublin: Department of Health and Children

Mutepfa, M. Mhaka (2009). Spousal abuse in Zimbabwe: nature and extent across socio-economic class. Gender and Religiosity. Zimbabwe Psychological Association

Namadi, M. (2006). Nature and prevalence of domestic violence against men in Dala local government area of Kano State, Nigeria. Retrieved on the 23th of February, 2018 from https://www.oer.fukashare.edu.ng

Nwachukwu, J.O. (2018). 30 year old woman sentenced to death for killing own husband. Daily post newspaper, $8 / 2 / 2018$.

Nwafor, P. (2018). Diamond estate murder. Udeme planned to travel abroad after killing her husband retrieved from https.//vanguardngr.com. $8^{\text {th }}$ May, 2018.

Obarisiagbon, E.I. (2017). Sex: a stability factor in marriage. Being a paper/talk delivered at the family week of

Osazuwa, J. and Iboma, B. (2018). From lovers to husband killers: why woman murder their spouses, by experts. Retrieved on the 17 May, 2018. From https://www.sunnewsonline.com.

Oti, B. Paul, S. Duru, T. (2017). The emerging trend in culture of domestic violence in Nigeria: causes, theoretical assumptions and implications. Research Journal of Humanities, Legal Studies and International Development, 2(1): 53-63

Quinn, D.M. (1997). Intimate Partner Violence stigmatization model and barriers to help seeking.Basic and Applied Social Psychology, 94:634-651

Smith, E.L. (2002). The impact of domestic violence on urban preschool children battered mothers' perspective. Journal of Interpersonal Violence, 17(10):1075-1101

Swan, S.C., and Snow, D.L.(2003). Behavioural and psychological differences among abused women who use violence in intimate relationships. Violence against Women. 9:75-109

Watts, C. and Zimmerman, C. (2002). Violence against women: global scope and magnitude Lancet, 359: 1232-1237

World Health Organization (2002). World report on violence and health: summary. Retrieved February, 12011 from http://www.who.int/violence_injury_prevention/violence/world- report/en/summary-en.p.df 